\title{
Initial Treatment of Patients with Primary Breast Cancer: Evidence, Controversies, Consensus
}

Spectrum of Opinion of German Specialists at the 15th International

St. Gallen Breast Cancer Conference (Vienna 2017)

\section{Erstbehandlung von Patientinnen mit primärem Mammakarzinom: Evidenz, Kontroversen, Konsens}

\author{
Meinungsbild deutscher Experten zur 15. Internationalen \\ St. Gallen-Konsensuskonferenz (Wien 2017)
}

Authors

Michael Untch ${ }^{1}$, Jens Huober ${ }^{2 *}$, Christian Jackisch ${ }^{3}$, Andreas Schneeweiss ${ }^{4}$, Sara Y. Brucker ${ }^{5 *}$, Peter Dall ${ }^{6}$, Carsten Denkert $^{7 *}$, Peter A. Fasching ${ }^{8}$, Tanja Fehm ${ }^{9}$, Bernd Gerber ${ }^{10}$, Wolfgang Janni ${ }^{11}$, Thorsten Kühn ${ }^{12}$,

Diana Lüftner ${ }^{13}$, Volker Möbus ${ }^{14}$, Volkmar Müller ${ }^{15}$, Achim Rody ${ }^{16}$, Peter Sinn ${ }^{17}$, Marc Thill ${ }^{18}$, Christoph Thomssen ${ }^{19}$, Nadia Harbeck ${ }^{20 *}$, Cornelia Liedtke ${ }^{21}$

\section{Affiliations}

1 Klinik für Gynäkologie und Geburtshilfe, interdisziplinäres Brustzentrum, HELIOS Klinikum Berlin Buch, Berlin, Germany

2 Universitätsfrauenklinik Ulm, Brustzentrum, Ulm, Germany

3 Klinik für Gynäkologie und Geburtshilfe, Sana-Klinikum Offenbach, Offenbach, Germany

4 Nationales Centrum für Tumorerkrankungen (NCT) und Universitätsklinikum, Heidelberg, Germany

5 Universitäts-Frauenklinik Tübingen, Tübingen, Germany

6 Frauenklinik am Klinikum Lüneburg, Lüneburg, Germany

7 Pathologisches Institut und Deutsches Konsortium für Translationale Krebsforschung (DKTK), Charité Universitätsmedizin Berlin, Berlin, Germany

8 Frauenklinik des Universitätsklinikums Erlangen, Comprehensive Cancer Center Erlangen-EMN, Friedrich-Alexander Universität Erlangen-Nürnberg, Erlangen, Germany

9 Universitätsfrauenklinik Düsseldorf, Düsseldorf, Germany

10 Universitätsfrauenklinik Rostock, Rostock, Germany

11 Universitätsfrauenklinik Ulm, Ulm, Germany

12 Klinik für Frauenheilkunde und Geburtshilfe, Klinikum Esslingen, Esslingen, Germany

13 Medizinische Klinik mit Schwerpunkt Hämatologie, Onkologie und Tumorimmunologie, Charité Berlin, Campus Benjamin Franklin, Berlin, Germany

14 Klinik für Gynäkologie und Geburtshilfe, Klinikum Frankfurt-Höchst, Frankfurt/Main, Germany

15 Klinik und Poliklinik für Gynäkologie, Universitätsklinikum Hamburg-Eppendorf, Hamburg, Germany

* $\quad$ St. Gallen Panel Expert
16 Klinik für Frauenheilkunde und Geburtshilfe, Universitätsklinikum Schleswig-Holstein/Campus Lübeck, Lübeck, Germany

17 Institut für Pathologie, Universitätsklinikum Heidelberg, Heidelberg, Germany

18 Klinik für Gynäkologie und Geburtshilfe, Interdisziplinäres Brustzentrum, Agaplesion Markus Krankenhaus, Frankfurt/Main, Germany

19 Universitätsklinik und Poliklinik für Gynäkologie, Halle (Saale), Germany

20 Brustzentrum, Frauenklinik der Universität München (LMU), München, Germany

21 Klinik für Frauenheilkunde und Geburtshilfe, Universitätsklinikum Schleswig-Holstein, Campus Lübeck, Lübeck, Germany

Key words

St. Gallen consensus 2017, early breast cancer, systemic therapy, local therapy, multigene expression, pathology, pregnancy, male breast cancer

Schlüsselwörter

St. Gallen-Konsensus 2017, frühes Mammakarzinom, systemische Therapie, lokale Therapie, Multigenexpression, Pathologie, Schwangerschaft, Brustkrebs beim Mann

received 25.4.2017

revised $\quad 2.5 .2017$

accepted 16.5.2017

Bibliography

DOI https://doi.org/10.1055/s-0043-111601

Geburtsh Frauenheilk 2017; 77: 633-644 @ Georg Thieme

Verlag KG Stuttgart · New York | ISSN 0016-5751 


\section{Correspondence}

Prof. Michael Untch

HELIOS Klinikum Berlin-Buch, Klinik für Gynäkologie und Geburtshilfe, Multidisziplinäres Brustzentrum

Schwanebecker Chaussee 50, 13125 Berlin, Germany michael.untch@helios-kliniken.de

$\oplus$

Deutsche Version unter:

https://doi.org/10.1055/s-0043-111601

\section{ABSTRACT}

The St. Gallen International Consensus Conference on the treatment of patients with primary breast cancer has been held regularly (every second year in the last six years) for more than 30 years. This year, the findings of the International St. Gallen Consensus Panel and their implications for clinical practice were again discussed by a German working group of leading breast cancer specialists. Five of the breast cancer specialists from Germany were also members of this year's St. Gallen panel. A comparison between the St. Gallen recommendations and the annually updated treatment guidelines of the Gynecologic Oncology Group (AGO 2017) and the S3guideline agreed upon in 2017 is useful. The recommendations of the St. Gallen panel represent an international crosssection of opinions of experts from different countries and different disciplines, while the S3-guideline and AGO guidelines are evidence-based. The motto of this year's 15th
St. Gallen Conference was "Escalating and De-Escalating". The rationale behind this concept was to promote more individualized treatment and thereby reduce overtreatment as well as undertreatment.

\section{ZUSAMMENFASSUNG}

Seit über 30 Jahren findet regelmäßig (in den letzten 6 Jahren alle 2 Jahre) die internationale St. Gallen-Konsensuskonferenz zur Behandlung von Patientinnen mit primärem Mammakarzinom statt. Die Ergebnisse des internationalen St. Gallen-Konsensus-Panels wurden auch dieses Jahr wieder von einer deutschen Arbeitsgruppe führender Brustkrebsexperten für den Klinikalltag in Deutschland diskutiert. Fünf der Brustkrebsexperten aus Deutschland sind zugleich Mitglieder des diesjährigen St. Gallen-Panels. Der Vergleich der St. Gallen-Empfehlungen mit den jährlich aktualisierten Therapieempfehlungen der Arbeitsgemeinschaft Gynäkologische Onkologie (AGO-Mamma 2017) und der aktuell im Jahre 2017 abgestimmten S3-Leitlinie ist sinnvoll. Die Empfehlungen des St. Gallen-Panels stellen ein Meinungsbild von Experten unterschiedlicher Länder und Fachdisziplinen dar, wohingegen S3Leitlinie und AGO-Empfehlungen evidenzbasiert sind. Die diesjährige 15. St. Gallen-Konsensuskonferenz stand unter dem Motto „Escalating and De-Escalating“, das sich durch alle Therapiebereiche zog, die zur Abstimmung standen. Ziel war es, Patientinnen individuellere Therapieoptionen anzubieten und das Risiko einer Über- bzw. Untertherapie zu vermeiden.

\section{Introduction}

The panel of this year's 15th St. Gallen Consensus Conference on the initial treatment of primary breast cancer consisted of 72 specialists on breast cancer from 24 countries, making the panel significantly larger than in previous years. Five members of the panel are from Germany. Since 30 years the recommendations of the St. Gallen Consensus Conference have attracted much interest worldwide. This is still the case, even though evidence-based guidelines are becoming increasingly important.

The St. Gallen recommendations are based on majority votes by the panelists. The panelists vote on questions which are put to the vote; they have the option of voting "yes" (agreement), "no" (rejection) or "abstain" (insufficient data, no opinion possible). Other questions may require panelists to choose between several different options. The questions and topics which were put to the vote were chosen by the St. Gallen Committee. The aim is to obtain the opinion of the majority of the panel members based on their own practical experience and, ideally, to use this to create an international consensus for clinical practice.

As the St. Gallen panelists work in different disciplines and come from different countries with different healthcare systems and resources, the consensus essentially reflects the opinions of these specialists. Voting by the panel aims to take account of the currently available evidence. With that in mind, for several years a German working group has regularly commented on the voting results of the St. Gallen panelists and the implications for clinical practice in Germany. The comments given by the German working group also take the current treatment guidelines of the Breast Commission of the Gynecologic Oncology Group (AGO) [1] into account; this year, the update of the S3-guideline which is due to be completed shortly was also included in the comparison.

\section{Basis of the St. Gallen consensus}

The motto of the 15th St. Gallen Consensus Conference was "Escalating and De-Escalating". Given the fact that our understanding of tumor biology is becoming ever more detailed and that therapy is now based on this more detailed information, the focus was on developing strategies which could be used to select the appropriate treatment for individual patients from a range of available options; the aim is to avoid the risk of overtreatment or undertreatment. The choice of treatment is guided by analyzing which patients require more intensive treatment and which patients can have reduced treatment without leading to a worsening of their prognosis.

\section{Surgical Issues}

The focus of the surgical questions in primary breast cancer was on adequate margin of resection and on the right surgical approach in the axilla. 


\section{Resection margins for DCIS}

If a patient with histologically confirmed ductal carcinoma in situ (DCIS) undergoes breast-conserving surgery (no invasive carcinoma present) and adjuvant radiation of the breast is planned, a second resection is not required if there was no ink on tumor (R0) and the histologically confirmed tumor-free margin is of at least $2 \mathrm{~mm}$. This should not be understood to indicate that a second resection is necessary for smaller tumor-free margins; the decision whether second resection is required depends on the individual case and on the assessment by an interdisciplinary team.

The German group of experts agree with the majority vote of the St. Gallen panelists. The German specialists refer to the AGO 2017 guidelines [1]: the guidelines propose that if the tumor-free resection margin is less than $2 \mathrm{~mm}$ a second resection is discussed with the patient. According to the AGO guidelines, the majority of patients with DCIS should undergo adjuvant radiation of the breast after breast-conserving surgery (BCS). However, it is important to note in each individual case that radiotherapy reduces the risk of local recurrence but probably does not affect the probability of overall survival [1] except in higher-risk cases.

\section{Multifocal or multicentric breast cancer}

It is generally agreed that patients with invasive early breast cancer and multifocal (more than two lesions in a single quadrant) or multicentric (lesions in more than one quadrant) disease can have breast-conserving surgery if the margins of the resected tumors are clear (tumor-free resection margins) and they subsequently undergo adjuvant radiation of the breast. According to the AGO 2017 guidelines [1], the decision to carry out BCS in patients with multicentric breast cancer must be taken on a case-by-case basis and should depend on the number of lesions present.

The German specialists also agree with the St. Gallen vote that the required width of the tumor-free resection margin was not affected by the underlying tumor biology.

\section{Postoperative resection margins after neoadjuvant chemotherapy (NACT)}

Patients with early breast cancer who have complete tumor regression (ycT0) after NACT can subsequently undergo breast-conserving surgery. Control imaging and preoperative marking should be done prior to surgery, which is then carried out within the "new margins". It is not necessary to remove the entire tumor bed of the initial primary tumor. The prerequisite for this approach is that patients undergo adjuvant radiotherapy of the operated breast.

According to the majority vote of the St. Gallen panelists, reresection is not required in these patients if the margins are completely clear (no tumor cells in the resection margin is sufficient). According to the majority vote, this also applies to patients with multifocal residual tumor in the resected surgical specimen. The German experts add that this minimum requirement must be complied within all cases, and that in individual cases, even if the margin is tumor-free on microscopic examination, second resection should still be considered if there is any suspicion of residual tumor, although this decision should be taken by an interdisciplinary (clinical pathology) tumor board. This also applies if only partial radiation of the tumor bed was done but pathological exami- nation found no residual tumor. An interdisciplinary tumor board should decide whether this corresponds to complete remission or whether second resection of the tumor bed is necessary to ensure that there is no residual tumor.

Nipple areola-sparing mastectomy can be carried out after the patient has completed neoadjuvant systemic therapy. Here the German experts agree with the majority vote of the St. Gallen panel.

\section{No Axillary Dissection - for Which Patients?}

With the introduction of sentinel node biopsy (SNB), axillary lymph node dissection (ALND) has become less important. Since then, the discussion has focused on when ALND is not required. Because of the significant side effects of this invasive procedure (pain, hematoma, restricted mobility, chronic lymphedema) the potential benefit needs to be clearly defined.

The German experts agree with the majority of St. Gallen panelists that ALND is not recommended for patients with 1-2 positive sentinel lymph nodes (i.e. with macrometastasis) if the patient is scheduled to undergo tangential field radiotherapy postoperatively following BCS or post-mastectomy radiotherapy of the thoracic wall with tangential coverage of part of the axillary lymph nodes. Treatment of these patients must additionally include adequate systemic therapy.

The St. Gallen panelists did not differentiate between axillary radiotherapy of the lymph nodes with standard radiotherapy or with high tangent radiation to treat patients who had BCS. In both cases, ALND is not necessary according to the St. Gallen consensus. The German experts agree with this consensus [2]. They add that reducing the extent of surgery should not lead to increased radiation therapy. The German experts refer in this context to the careful differentiations made in the AGO 2017 guidelines ( $\triangleright$ Fig. 1) [1]. Patients with 1-2 affected sentinel lymph nodes (SLN) who do not undergo ALND should receive conventional breast radiotherapy. As hypofractionated radiotherapy is increasingly used in Germany, these patients should be included in the INSEMA trial.

The St. Gallen panelists and the German experts agree that tumor biology (lymph node infiltration, hormone receptor status, grading) of patients with 1-2 positive SLN does not affect the decision to perform ALND.

\section{ALND after NACT}

The German experts agree with the majority vote of the St. Gallen panel that for patients who have clinically unsuspicious axillary lymph nodes (on palpation and/or sonography) at primary diagnosis (cN0), SNB after neoadjuvant therapy is recommended and ALND is not indicated. The German experts recommend that in addition to palpation, sonography should be an indispensable part of the pre-treatment assessment of the axilla. The German experts also agree with the St. Gallen panel that for patients with clinically negative axillary lymph nodes scheduled for NACT, SNB should be carried out after NACT rather than before.

This would mean that many patients (about $30 \%$ have a positive SLN before NACT) would be spared ALND who would otherwise - given the finding of a positive SLN prior to NACT - have 


\begin{tabular}{|c|c|c|c|}
\hline \multicolumn{4}{|c|}{ Axillary lymph node dissection ALND I } \\
\hline & \multicolumn{3}{|c|}{$\begin{array}{l}\text { Oxford/AGO } \\
\text { LoE/GR }\end{array}$} \\
\hline \multicolumn{4}{|l|}{ Axillary lymph node dissection } \\
\hline $\begin{array}{l}\text { Endpoint: survival } \\
\text { (with adequate multimodal therapy) }\end{array}$ & 3 & D & - \\
\hline Endpoint: staging & 3 & A & - \\
\hline Endpoint: locoregional tumor control & $2 a$ & A & $+1-$ \\
\hline \multicolumn{4}{|l|}{ Axillary lymph node dissection for } \\
\hline$D$ DCIS & $2 b$ & B & -- \\
\hline If SLN excision is possible & $1 \mathrm{a}$ & A & -- \\
\hline $\begin{array}{l}\text { SN positive } \\
\text { ( } \mathrm{CT} 1 / 2 \mathrm{cNO} 0^{*},<3 \mathrm{SN}+, \mathrm{BCT}+\text { tangential } \\
\text { radiation, adequate systemic therapy) }\end{array}$ & $1 \mathrm{~b}$ & B & $+1-$ \\
\hline $\mathrm{SN}+$ (microscopic) & $1 b$ & A & - \\
\hline$>\mathrm{SN}(\mathrm{i}+)$ & $2 b$ & B & -- \\
\hline $\begin{array}{l}\text { SN + mastectomy } \\
\text { (no radiation of the thoracic wall) }\end{array}$ & $1 b$ & B & + \\
\hline \multicolumn{4}{|l|}{$\begin{array}{l}\text { SN + mastectomy } \\
\text { (radiation of the thoracic wall) }\end{array}$} \\
\hline Only if $\mathrm{T} 1, \mathrm{~T} 2$ and $1-2$ positive SLN & 5 & D & $+1-$ \\
\hline \multicolumn{4}{|l|}{ - Axilla dissection indicated but not possible } \\
\hline Radiation analogous to AMAROS trial & $1 b$ & B & + \\
\hline
\end{tabular}

- Fig. 1 AGO 2017 guidelines on axillary lymph node dissection (ALND) in primary invasive breast cancer [1]. With the kind permission of AGO Breast.

had ALND. Both the AGO guidelines [1] and the St. Gallen consensus recommend ALND [3] for patients who have positive SLN after NACT. The indication for adjuvant radiotherapy does not just depend on tumor size but increasingly also on biological factors. This recommendation should definitely be discussed with the radiation therapist. German breast centers repeatedly claim that evaluating SLN prior to NACT is important to determine whether postoperative irradiation of the thoracic wall and the regional lymph nodes is indicated when examination shows SLN involvement. The procedure should not be recommended because it would cause an overtreatment in $30 \%$ of patients.

The question whether SNB is sufficient in patients with suspicious lymph nodes $(\mathrm{i} / \mathrm{cN}+)$ on palpation and/or sonography at primary diagnosis but which are clinically/sonographically unremarkable (ycNO) after NACT ("down-staging": axillary conversion after NACT) and whether (or even when) complete ALND should be carried out has been discussed intensively. Histological confirmation of these suspicious lymph nodes should be attempted with punch biopsy. The German experts agree with $54 \%$ of the St. Gallen panelists that SNB is not sufficient for patients who have 1-2 involved axillary lymph nodes after NACT. ALND should be performed if macrometastasis are present in one or more SLN after NACT.
Both groups agree that in certain situations SNB alone can be considered in patients $(\mathrm{i} / \mathrm{cN}+$ ) with axillary conversion to yicNO after NACT. Certain methods such as clip marking of the involved lymph nodes prior to carrying out NACT can lower the false-negative rate. The "plus/minus" option in the AGO 2017 guidelines [1] can be used in selected cases to avoid ALND. The German experts emphasize that these methods require further study under controlled conditions, e.g. in the context of the upcoming prospective multicenter SenTa register study of AGO and the German Breast Group (GBG).

\section{Adjuvant Radiation}

\section{Hypofractionated breast radiation following BCS now standard}

At the St. Gallen conference, the questions on adjuvant radiation therapy focused on whether it is possible to reduce the extent of radiation while offering the same efficacy and in which clinical situations this would be feasible. According to the majority vote of the St. Gallen panelists, the standard option after BCS is hypofractionated whole breast radiation. According to the vote, this particularly applies to patients older than 50 years. The German experts agree with the respective vote and refer to the current AGO 2017 guidelines [1].

AGO has recommended hypofractionated radiation on a high level (LoE: 1a A, GR: ++) [1]. A total dose of 40 Gy should be delivered in 15-16 fractions over 3-4 weeks. Conventional radiation therapy delivers a total dose of 50 Gy given in 25-28 fractions over 5-6 weeks. In the AGO 2017 guidelines, conventional radiation therapy has a lower grade of recommendation [1]. From 2017 on, patients should be informed about the significantly shorter duration of radiation, and breast centers should implement the new recommendations.

\section{Is partial-breast radiation after BCS an option?}

According to the majority of St. Gallen panelists, partial-breast radiation after BCS (without whole breast radiation) should only be the definitive radiation treatment if patients can be classified as "suitable" based on the criteria of the ASTRO (American Society of Radiation-Oncology) or ESTRO (European Society for Radiotherapy \& Oncology) $[4,5]$. The German experts do not entirely agree with this vote and refer to the AGO guidelines on patients older than 70 years of age [1]. In the opinion of the German panel of experts, the indication for patients between the ages of 50 and 70 years is clear. The decision to opt for partial-breast radiation must be taken on a case-by-case basis and must be discussed with the patient ( $\bullet$ Fig. 2) [1].

The ASTRO classifies the following patients as suitable: age $\geq 60$ years, no BRCA $1 / 2$ mutation, ER+, tumor size $\leq 2 \mathrm{~cm}$ (T1), tumor-free resection margin $\geq 2 \mathrm{~mm}$, N0, no lymph node invasion, unicentric/unifocal, invasive-ductal or other favorable histology (mucinous, tubular, colloid), no extensive intraductal component. The criteria of the ESTRO differ only minimally with regard to age ( $\geq 50$ years) and T-stage (pT1-2) [4-7].

A narrow majority of the St. Gallen panelists do not recommend partial-breast irradiation as the sole radiotherapy modality 


\begin{tabular}{|c|c|c|c|}
\hline \multicolumn{4}{|c|}{$\begin{array}{l}\text { Boost and partial-breast radiation } \\
\text { after BCS for invasive cancer }\end{array}$} \\
\hline & \multicolumn{3}{|c|}{$\begin{array}{l}\text { Oxford/AGO } \\
\text { LoE/GR }\end{array}$} \\
\hline \multicolumn{4}{|l|}{$\begin{array}{l}\text { Boost radiation of the tumor bed } \\
\text { (improved local control, no survival benefit) }\end{array}$} \\
\hline premenopausal & $1 b$ & B & ++ \\
\hline $\begin{array}{l}\text { post-menopausal, } \\
\text { if }>\text { T1, G3, HER2-positive, triple- } \\
\text { negative, extensive intraductal compo- } \\
\text { nent (EIC) (at least one factor present) }\end{array}$ & $2 b$ & B & + \\
\hline \multicolumn{4}{|c|}{$\begin{array}{l}\text { Intraoperative radiotherapy (IORT) (intraoperative accelerated } \\
\text { partial breast irradiation [APBI]) }\end{array}$} \\
\hline $\begin{array}{l}\text { As boost radiation prior to whole-breast } \\
\text { irradiation }\end{array}$ & $2 a$ & B & + \\
\hline \multicolumn{4}{|l|}{$\begin{array}{l}\text { As sole radiotherapy modality } \\
(\text { IORT } 50 \mathrm{kV} \text {, intraoperative extended } \\
\text { radiotherapy [IOERT] })^{* *}\end{array}$} \\
\hline$>>50$ years $* *$ & $1 \mathrm{a}$ & A & $+\mid-*$ \\
\hline$>70$ years $* *$ & $1 \mathrm{a}$ & A & + \\
\hline \multicolumn{4}{|c|}{$\begin{array}{l}\text { Postoperative part-breast irradiation as the sole radiotherapy } \\
\text { modality in selected patients (APBI) }\end{array}$} \\
\hline Interstitial brachytherapy & $1 \mathrm{~b}$ & B & $+1-^{*}$ \\
\hline$>70$ years ${ }^{* *}$ & $1 b$ & B & + \\
\hline Intracavitary balloon technique & $2 b$ & B & $-{ }^{*}$ \\
\hline $\begin{array}{l}\text { Intensity modulated radiotherapy } \\
\text { (IMRT)*** }\end{array}$ & $2 b$ & B & $-^{*}$ \\
\hline \multirow{2}{*}{\multicolumn{4}{|c|}{$\begin{array}{l}{ }^{*} \text { Study participation recommended } \\
{ }^{* *} \text { Only for pT1 pN0 R0 G1-2, HR+, non-lobular, > } 50 \text { years, } \\
\text { no extensive DCIS, IORT during first surgery }\end{array}$}} \\
\hline & & & \\
\hline$* * *$ No long-term data available & & & \\
\hline
\end{tabular}

- Fig. 2 AGO 2017 guidelines on partial-breast radiation after breast-conserving surgery (BCS) for primary invasive breast cancer [1]. With the kind permission of AGO Breast.

after BCS was not indicated for patients whom the ESTRO classifies as "intermediate" and the ASTRO as "cautionary" $[4,5]$. The German experts agree with the St. Gallen recommendation.

The German experts point out that partial-breast irradiation as the sole radiotherapy treatment is currently not standard in Germany. It may be administered as sole radiotherapy modality only in selected cases for patients with a favorable tumor biology and a low risk of recurrence (pT1 pN0 R0 G1-2, HR+, non-lobular, age $>50$ years, no extensive DCIS) as interstitial brachytherapy or intraoperatively [1].

Boost irradiation of the tumor bed after resection of the primary tumor is not necessary if the patient is older than 60 years of age and has no increased risk (low grade, favorable biology, low multigene score). The German experts agree with the vote of the St. Gallen panelists.

\section{Radiotherapy (RT) of locoregional lymph nodes (SCG/ICG)}

\begin{tabular}{|c|c|c|c|}
\hline & \multicolumn{3}{|c|}{$\begin{array}{c}\text { Oxford/AGO } \\
\text { LoE/GR }\end{array}$} \\
\hline \multicolumn{4}{|c|}{ RT to supraclavicular/infraclavicular lymphatic regions } \\
\hline > pN2a or level III involvement & $1 a$ & A & ++ \\
\hline pN1a high risk* & $2 a$ & B & + \\
\hline \multicolumn{4}{|c|}{ * Central or medial tumor location, and G2-3 or ER/PR-negative } \\
\hline \multicolumn{4}{|c|}{ * premenopausal, lateral location, and G2-3 or ER/PR-negative } \\
\hline pN0 premenopausal, high risk** & $2 a$ & B & $+1-$ \\
\hline \multicolumn{4}{|c|}{ ** Central or medial tumor location, and G2-3, and ER/PR-negative } \\
\hline $\begin{array}{l}\text { After NACT/NAT (indications as } \quad \text { AGO }^{1} \\
\text { for post-mastectomy RT [PMRT]) }\end{array}$ & $2 b$ & B & $+1-$ \\
\hline $\begin{array}{l}\text { After NACT/NAT if cN+ } \\
\text { (core needle/fine needle biopsy } \\
\text { [CNB/FNA]) (indications as for PMRT) }\end{array}$ & $2 b$ & A & + \\
\hline
\end{tabular}

- Fig. 3 AGO 2017 guidelines on adjuvant radiotherapy of the regional lymph nodes in primary invasive breast cancer [1]. With the kind permission of AGO Breast.

\section{Which patients require more extensive radiation volumes?}

The German experts agree with the St. Gallen majority vote whereby patients after BCS who have four or more involved lymph nodes should receive adjuvant radiation of the non-axillary lymph nodes with additional radiation of the supraclavicular and infraclavicular lymph nodes. If $1-3$ lymph nodes are involved, $54 \%$ of the St. Gallen panelists recommended adjuvant radiation of the nonaxillary regional lymph nodes if the patient had a higher risk, e.g., unfavorable tumor biology. The German experts agree with this opinion and refer to the current AGO guidelines ( $\bullet$ Fig. 3) [1].

\section{Adjuvant post-mastectomy radiotherapy}

Adjuvant post-mastectomy radiotherapy includes radiation of the thoracic wall and the regional lymph nodes. The German experts do not generally agree with the two narrow majority votes of the St. Gallen panelists who stated that adjuvant radiation must be standard treatment

1. after mastectomy in patients with no lymph node involvement (pNO) and a tumor size of $5 \mathrm{~cm}$ or above, and

2. in all patients who have involvement of 1-3 lymph nodes

The German experts refer to the AGO guidelines [1] which state that this should only apply to patients who have additional risk factors or an increased risk of recurrence ( $\bullet$ Fig. 4).

The German experts point out that adjuvant radiation (of the thoracic wall and regional lymph nodes) after mastectomy is only standard for patients with 1-3 involved lymph nodes and additional risk factors (unfavorable tumor biology, or younger age $[<40$ years]) and for patients with positive SNB who had not had ALND. In the latter case, the German experts again refer to the 


\section{Indication for thoracic wall radiotherapy (PMRT) for patients with 1-3 axillary lymph node metastases}
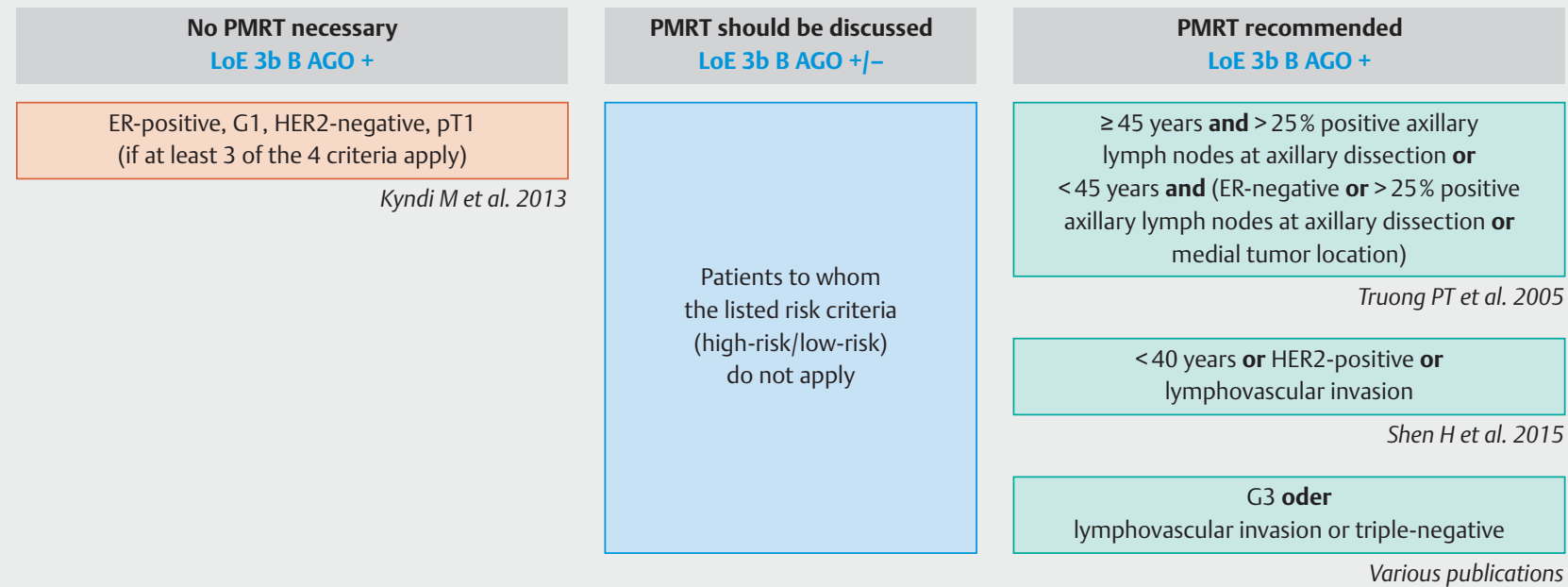

Note: "If irradiation of the lymphatic drainage pathways is indicated, then the thoracic wall should also be irradiated."

- Fig. 4 AGO 2017 guidelines on the indications for radiation of the thoracic wall in patients with primary invasive breast cancer and

1-3 involved metastases in the axillary lymph nodes [1]. With the kind permission of AGO Breast.

current AGO guidelines [1] which state that ALND is the preferred option for these patients - despite the higher risk of comorbidities. A re-assessment of the AMAROS trial [8] will offer additional information whether radiotherapy on the regional lymph nodes after mastectomy in patients with involved SLN is as safe as ALND without radiation therapy.

\section{Radiotherapy after neoadjuvant systemic therapy}

According to the St. Gallen consensus, the indication for adjuvant radiation after neoadjuvant systemic therapy is based on the stage of disease before and after neoadjuvant therapy (78\%). The German experts agree with this opinion but qualified their agreement by pointing out that prospective randomized data on this are lacking. In the majority of cases in Germany, only the clinical stage prior to starting neoadjuvant therapy is taken into account when deciding whether postoperative radiation therapy is indicated. From a German perspective, this point requires additional clinical study. The results of the randomized NSABP B-51 study will offer further insights but will only be available in a few years.

\section{Pathology}

\section{Is traditional pathology enough?}

In unclear cases multigene expression analysis should help to make the treatment more individual. The question in this context is whether traditional pathological parameters such as hormone receptor (HR) status, HER2-status, grading, or proliferation index (Ki-67) as well as immunohistochemistry in general are still sufficient as exclusive basis for therapeutic decisions concerning breast cancer subtypes.
For the differentiation between luminal A-like and luminal Blike (HER2-negative) breast cancer patients based on immunohistochemistry, the St. Gallen panelists voted unanimously that this is important for tumor biology evaluation. According to the majority vote, the differentiation provides clinically relevant information for the appropriate therapy. The German experts agree with both statements but pointed to the methodological problems involved in subtyping using only immunohistochemistry [1]. Referring to the AGO guidelines, the German experts point out that currently there is no generally accepted pathohistological marker of the intrinsic subtypes defined by gene expression. Nevertheless, immunohistochemical subtyping can offer some guidance in clinical practice when deciding on the appropriate treatment [1].

Classification into luminal A-like or luminal B-like cancer can according to the majority vote of the St. Gallen panelists - be done immunohistochemically based on estrogen and progesterone receptor status (ER and PR) as well as the degree of differentiation (grading). The majority of the St. Gallen panelists voted for additional determination of the Ki-67 proliferation index in addition to HR status as criterion for classifying tumors as luminal Alike or luminal B-like. The German experts agree with this but point to the methodological problems involved in Ki-67 determination [1]. The St. Gallen panelists did not vote on a cut-off for $\mathrm{Ki}-67$ in 2017. Some of the St. Gallen panelists pointed out that differentiating between luminal A-like and luminal B-like cancers could also be done with multigene expression analysis. The German specialists supported this suggestion.

\section{Significance of tumor-infiltrating lymphocytes (TILs)}

The importance of tumor-infiltrating lymphocytes (TILs) for triplenegative or HER2-positive early breast cancer has been discussed 
for years. As the extent of lymphocyte infiltration has no clinical consequences, the detection of TILs does not currently have to be included in the pathologist's report. The German experts agree with the majority vote of the St. Gallen panelists but point to the potential importance of TILs as markers for the immunogenicity of certain breast cancer subtypes.

\section{Importance of multigene expression signature for prognosis}

In patients with hormone-sensitive primary breast cancer, the question whether patients with a high risk of recurrence ("at risk" situation) require chemotherapy in addition to endocrine treatment comes up regularly in clinical practice. With their vote the St. Gallen panelists confirmed that multigene expression analysis is not indicated in patients with ER-positive, HER2-negative, welldifferentiated $\mathrm{pT1a/b}$ cancer without lymph node involvement and with a low Ki-67 proliferation index. The German experts added that multigene expression testing is only justified if - based on classic histopathological findings - it is not possible to decide whether chemotherapy is indicated.

Other votes at the St. Gallen Consensus Conference dealt with the currently available multigene expression analyses OncotypeDX ${ }^{\circledR}$ Recurrence Score (RS), MammaPrint $70^{\circledR}$ (MP), Prosigna ${ }^{\circledR}$ PAM 50 Risk of Recurrence Score (ROR), EndoPredict ${ }^{\circledR}$ (EP) and the Breast Cancer Index (BCI), which is currently not available in Germany. Almost all questions went to a separate vote for each specific assay but results were similar overall.

The overwhelming majority of St. Gallen panelists viewed the above-listed and currently available multigene expression tests (RS, MP, ROR, EP, BCl) as an opportunity to obtain information which will be prognostically relevant for patients with ER-positive/HER2-negative early breast cancer, irrespective of whether patients had lymph node involvement or not. The German experts agree with the St. Gallen panelists but add the caveat that $\mathrm{BCl}$ is not relevant for Germany as it is currently not available there.

\section{Multigene expression signatures and the indication for chemotherapy}

For patients with node-negative cancer or 1-3 involved lymph nodes ( $\mathrm{pN0} / 1 \mathrm{a})$, the currently available multigene expression tests can contribute to a more realistic assessment of prognosis, according to the majority vote of the St. Gallen panelists, an opinion with which the German experts concur. Whether it is indeed possible to base the decision for or against chemotherapy on the results of multigene expression testing was confirmed by $59 \%$ of the St. Gallen panelists for the RS test, $43 \%$ for the Mammaprint, $47 \%$ for the PAM 50 test, and 16\% for the EPclin test. Differences in the assessment of the respective tests cannot be clearly deduced from the current data $[9,10]$. It also does not correspond to the AGO guidelines on the clinical usefulness of the tests as an aid to decision-making for or against adjuvant chemotherapy, as the guidelines do not differentiate between the yes/no of individual tests but only assess the level of evidence [1].

Half of the St. Gallen panelists would use multigene expression analysis in patients with no lymph node involvement when considering whether extended endocrine therapy (more than five years) is indicated. The other half of the panelists was of the opinion that multigene expression signatures do not offer a useful option when considering whether or not to prescribe extended endocrine therapy to these patients. The German experts agree with this and pointed out that multigene expression analysis primarily aims to make a prognostic statement rather than serve as the basis for treatment decisions. The current data do not allow any conclusions to be drawn on whether extended endocrine therapy offers benefits in cases with an increased risk of late recurrence (after 510 years and more).

\section{Adjuvant Endocrine Therapy}

\section{Importance of ovarian function suppression}

On the basis of the current data $[11,12]$, the St. Gallen panelists and the German experts agree that ovarian function suppression (OFS: GnRHa, bilateral ovarectomy) in addition to tamoxifen or an Al can be an option for premenopausal patients who have premenopausal estrogen levels in blood and/or have started to menstruate within eight months after (neo)adjuvant chemotherapy. The St. Gallen panelists had the opinion that additional adjuvant OFS was principally indicated in very young patients ( $<35$ years). The German experts criticize this exclusive focus on age as the data was obtained from retrospective, explorative analyses.

The German experts emphasize that the essential reason for prescribing OFS was persistent ovarian function after (neo)adjuvant chemotherapy and an increased risk of recurrence (e.g. four or more affected lymph nodes). They had the opinion that additional OFS should only be discussed with premenopausal patients who have an increased risk of recurrence.

If additional OFS is indicated, the question arises whether this should be administered in addition to tamoxifen or an aromatase inhibitor. The St. Gallen panelists and the German panel of experts agree that the combination of OFS plus an aromatase inhibitor could be an option for some patients. The St. Gallen vote therefore corresponds to the current AGO guidelines [1]. The German experts recommend that decision on additional OFS and on whether OFS should be combined with tamoxifen or with an aromatase inhibitor should be taken on a case-by-case basis after detailed discussions with the patient about benefits and risks. It should be noted that aromatase inhibitors must always be combined with OFS when treating premenopausal patients.

\section{Endocrine treatment of postmenopausal patients}

With regard to the treatment of postmenopausal patients, the German panel of experts agree with the St. Gallen panelists on all questions concerning adjuvant endocrine treatment. Thus, treatment with tamoxifen alone is still an adequate therapy option. However, especially for patients with increased risk, aromatase inhibitor-based therapy is the preferred option in the first five years. The German experts refer to the current AGO guidelines [1].

An increased risk which would support the upfront administration of an aromatase inhibitor would be, for example, a patient with lymph node involvement ( $\mathrm{pN}+$ ), G3 carcinoma or elevated Ki-67 expression. An aromatase inhibitor should be used upfront in patients with invasive lobular histology $[13,14]$. After complet- 
ing adjuvant chemotherapy, aromatase inhibitors should be considered if the patient is postmenopausal.

\section{Extended adjuvant endocrine therapy}

Extended adjuvant endocrine treatment for longer than five years is an important option for patients with increased risk of recurrence, irrespective of their menopausal status. For premenopausal patients who remain premenopausal during therapy, this means that they can be treated with tamoxifen for a total of ten years if they have an increased risk of recurrence at primary diagnosis. The German panel of experts agree with the majority vote of the St. Gallen panelists.

Treatment of postmenopausal patients who received tamoxifen over the first five years followed by an aromatase inhibitor should preferably consist of an aromatase inhibitor for a further 2-5 years if the patients have a moderate to high risk of recurrence. After they switch from tamoxifen to an aromatase inhibitor they will receive an aromatase inhibitor for at least five years and up to a maximum of eight years. The majority of St. Gallen panelists were opposed to further treatment with tamoxifen for patients with an increased risk of recurrence. The German panel of experts agree on most points. They once more refer to the current AGO guidelines [1] but consider that further treatment with tamoxifen could be an option for patients with poor tolerance of the aromatase inhibitor.

Patients who receive an aromatase inhibitor right from the start of treatment for a period of over five years as part of adjuvant endocrine therapy should continue to receive an aromatase inhibitor for a further three to five years if they have an increased risk of recurrence. The duration of extended endocrine therapy with an aromatase inhibitor should depend on the patient's tolerance of the aromatase inhibitor, the patient's individual risk profile, and the expected absolute benefit.

Even in this situation, the majority of the St. Gallen panelists opposed a switch to tamoxifen in the context of extended adjuvant endocrine therapy. As the upfront administration of an aromatase inhibitor is primarily an option for patients with an increased risk of recurrence, the St. Gallen panel also recommended not to stop endocrine adjuvant therapy after five years. The German panel of experts agree but again emphasize that continued treatment with tamoxifen can be an option when aromatase inhibitors are poorly tolerated [1]. As a general rule, there should be an early switch if there are significant side effects during endocrine therapy: If endocrine therapy is clearly indicated after the benefits and risks have been carefully weighed up, then any form of endocrine therapy is better than discontinuing treatment.

\section{Adjuvant Chemotherapy}

The St. Gallen vote on adjuvant chemotherapy focused on patients who might have a prognostic benefit from postoperative chemotherapy and should therefore receive chemotherapy postoperatively.

When considering patients without lymph node involvement (pN0), their prognosis as well as the decision for or against adjuvant chemotherapy should be based on immunohistochemical assessment of the tumor biology, which can be supplemented by multigene expression testing in cases of uncertainty. Relative indications for adjuvant chemotherapy are poorly differentiated G3 tumors, lymph node involvement $(\mathrm{pN}+)$, high Ki-67 proliferation index, very young patient age (<35 years) and low hormone receptor (HR) expression (<10\%). The German experts agree with the St. Gallen panelists and add that, based on these criteria, it is important to consider the risk-benefit-ratio.

The majority of St. Gallen panelists also considered extensive lymphovascular tumor invasion a relative indication for adjuvant chemotherapy. The German experts refer to the current AGO guidelines and state that lymphovascular tumor invasion is not an indication for chemotherapy [1]. From the German point of view chemotherapy is not necessarily indicated, if there are no additional risk factors.

\section{Luminal B-like breast cancer without HER2 overexpression}

For patients with luminal B-like breast cancer, a common question in clinical practice is whether adjuvant chemotherapy is indicated in addition to endocrine therapy. Adjuvant chemotherapy is indicated if there is an increased risk of recurrence [1]. The German experts agree with the majority of St. Gallen panelists that adjuvant chemotherapy should be recommended to patients with early luminal B-like breast cancer and prognostically unfavorable tumor biology confirmed by immunohistochemistry, irrespective of lymph node status. The German experts point out that in patients with no lymph node involvement tumor size should also be taken into account for treatment decision. If the primary tumor is very small (pT1a pN0) and there are no additional negative criteria, adjuvant chemotherapy is not indicated from the German point of view.

The St. Gallen panelists and the German experts confirm again that multigene expression analysis can be an effective method in patients with luminal-B-like breast cancer to determine whether the patient has an increased 10-year risk of metastasis and chemotherapy is therefore indicated. The majority of St. Gallen panelists voted that adjuvant chemotherapy is not necessary if RS is low as long as there is no lymph node involvement or if less than three nodes are involved. The German experts agree with this opinion and refer to the prospective data collected in the TAILORX trial which had a follow-up of five years [15]. The findings of this study have been confirmed by recent data from the West German Study Group (WSG) Phase III Plan B trial, which also had a followup of just under five years $[16,17]$.

The findings referred specifically to low-risk patients with an RS of less than 11 and no lymph node involvement or fewer than three involved lymph nodes and a follow-up of five years. If the RS score is intermediate, the St. Gallen panelists and the German specialists agree that avoiding adjuvant chemotherapy should only be considered in individual cases. For the final assessment (adjuvant chemotherapy indicated yes/no) it is necessary to wait until data on patients with intermediate scores are available from the TAILORx trial [15].

Initial prospective data on patients with 1-3 involved lymph nodes with a follow-up of just under five years are now also available for the MP score [18]. Based on preliminary data, adjuvant chemotherapy is not required for patients with 1-3 involved 
lymph nodes if the risk profile is low according to MP score. No prospective data are available yet for ROR and EP. However, according to retrospective data from prospective studies with EP, the cumulative risk of metastasis for low risk, node-positive patients (just under $20 \%$ of patients) who receive only endocrine therapy is about $5 \%$. This means that chemotherapy is not necessary in this patient population $[9,10]$. The German specialists additionally point out that results of the votes of the St. Gallen panelists were not always consistent with previous votes on multigene expression signatures.

The St. Gallen panelists and the German experts agree that adjuvant chemotherapy should be anthracycline-based and taxanebased for patients with luminal B-like (HER2-negative) breast cancer.

\section{Triple-negative breast cancer}

For patients with early invasive ductal triple-negative breast cancer (TNBC: ER-, PR-, HER2-), the established anthracycline/taxane-based regimens are the adjuvant therapy of choice. This applies irrespective of the underlying breast cancer phenotype and tumor stage (I-III) and, in the opinion of the German specialists, also applies to patients with or without germline mutations (BRCA1/2 mutation).

A narrow majority of the St. Gallen panelists had the opinion that TNBC is also an indication for platinum-based adjuvant chemotherapy. The German specialists do not agree with this vote as currently there is no data available which would justify the adjuvant administration of a platinum-based regimen. The German specialists therefore reject the use of $B R C A 1 / 2$ testing to determine whether carboplatin is indicated in an adjuvant setting. In the opinion of the German specialists, the decision whether adjuvant carboplatin is indicated must be taken on a case-by-case basis.

Patients with TNBC and no lymph node involvement who have a very small primary tumor (pT1a pN0) do not require adjuvant chemotherapy. The German panel of experts agree with the majority vote of the St. Gallen panelists on this point. They refer to data from recent trials [19-21] which showed a 10-year survival rate of more than $90 \%$ for TNBC patients with pT1a pN0 carcinoma. The German specialists additionally refer to the NCCN guidelines which also do not recommend chemotherapy for patients with pT1a carcinoma [22].

Dose-dense therapy (with G-CSF support) can be prescribed for patients with early TNBC, but the majority of the panelists voted that this is not the best option. The German panel of experts recommend that in general the treatment of patients with early TNBC should not primarily be adjuvant. If adjuvant chemotherapy is indicated, the AGO guidelines state that this treatment should be neoadjuvant [1]. The GeparSixto trial clearly showed that adding platinum in the neoadjuvant setting offered significant benefits for the pathologic complete response rate and for survival, irrespective of BRCA status [23].

\section{HER2-positive breast cancer}

Patients with early HER2-positive breast cancer as defined in the ASCO/CAP guidelines [24] and with lymph node involvement $(\mathrm{N}+)$ require chemotherapy in addition to anti-HER2 targeted treat- ment. According to the majority vote of the St. Gallen panelists, the therapy should be anthracycline- and taxane-based. The German specialists agree but also point to the benefits associated with the anthracycline-free $\mathrm{TCH}$ regimen (docetaxel, cyclophosphamide, trastuzumab). The $\mathrm{TCH}$ regimen is an effective treatment option which is associated with better cardiac tolerability compared to anthracycline/taxane-based regimens. This has been shown by the recently published 10-year data of the BCIRG 006 study [25]. AGO Breast therefore recommends the TCH regime as a valid therapy option [1]. The German specialists and the St. Gallen panelists agree that adjuvant chemotherapy should include a taxane.

According to the majority vote of the St. Gallen panelists, adjuvant anti-HER2 targeted therapy is generally indicated from tumor stage pT1b in patients with HER2-positive breast cancer without lymph node involvement (N0). The majority of patients with PT1a carcinoma do not require anti-HER2 targeted therapy. The German specialists agree with the St. Gallen panelists and refer to the current AGO guidelines [1].

The majority vote of the St. Gallen panelists and the German specialists agree, that when adjuvant chemotherapy is indicated for pNO carcinoma with HER2 overexpression, then weekly paclitaxel (twelve cycles) plus trastuzumab is a valid option. This applies to tumors with diameters of up to $2 \mathrm{~cm}$. Due to limited available data, the results of the vote were less clear-cut for tumors with diameters of $2-3 \mathrm{~cm}$. A majority of St. Gallen panelists considered the combination of docetaxel/cyclophosphamide plus trastuzumab a useful treatment option. The German specialists did not agree with this vote because the data for this regimen is still insufficient and the regimen is not recommended by AGO.

\section{Adjuvant anti-HER2 targeted therapy}

After receiving neoadjuvant chemotherapy in combination with trastuzumab/pertuzumab (dual antibody blockade), patients with HER2-positive breast cancer should receive further adjuvant treatment with trastuzumab. The duration of anti-HER2 targeted therapy should be one year including neoadjuvant therapy. At present, the adjuvant use of dual antibody blockade with trastuzumab/pertuzumab is not indicated. The German specialists agree with the respective majority votes of the St. Gallen panelists - but reserve their final opinion until the presentation of promising data from the APHINITY study at ASCO 2017. The data of APHINITY have been just published [26].

For the first time a vote was taken on the potential use of antiHER2 targeted biosimilar antibodies. The majority of St. Gallen panelists considered biosimilars - once they have been approved for use - as an acceptable option for (neo)adjuvant therapy to treat HER2-positive early breast cancer. The German specialists agree. Positive data have been presented in the meantime at this year annual meeting of the American Society of Clinical Oncology (ASCO) 2017 [27, 28].

\section{Neoadjuvant treatment for HER2-positive or triple-negative breast cancer}

The German specialists welcome the majority vote of the St. Gallen panelists on the importance of neoadjuvant systemic therapy. A clear majority of the panelists confirmed that neoadju- 
vant therapy should be the preferred therapy concept from stage II for patients with early HER2-positive breast cancer and patients with TNBC, even when breast-conserving surgery is possible. The St. Gallen vote on this issue corresponds to the AGO guidelines [1].

Patients with HER2-positive disease should receive taxanebased neoadjuvant chemotherapy plus anti-HER2 targeted treatment. More than $80 \%$ of panelists considered dual antibody blockade with pertuzumab/trastuzumab a recommended neoadjuvant therapy in combination with a taxane. Only around $30 \%$ would prescribe trastuzumab alone in addition to chemotherapy.

For patients with TNBC the St. Gallen panelists recommended neoadjuvant chemotherapy with platinum or an alkylating agent or sequential chemotherapy with anthracyclines and taxanes. The majority of St. Gallen panelists also considered albuminbound nab-paclitaxel followed by epirubicin/cyclophosphamide (EC) to be a possible neoadjuvant regimen for patients with early TNBC. In the GeparSepto trial, this regimen almost doubled the rate of pathologic complete response rate in TNBC patients compared to the control arm where patients received conventional paclitaxel followed by epirubicin/cyclophosphamide [29]. The German experts agree with the respective voting outcomes on the neoadjuvant treatment of HER2-positive and triple-negative breast cancer.

\section{Post-neoadjuvant Therapy}

Options for post-neoadjuvant therapy are currently being evaluated to treat those cases where anthracyceline-/taxane-based NACT does not result in pathologic complete remission (pCR). For patients with TNBC, $49 \%$ of the St. Gallen panelists recommended adjuvant treatment with capecitabine. The German specialists do not agree with this voting outcome which is based on data from the CREATE-X study [30].

The study [30] had shown a benefit for patients who received further treatment with capecitabine, but the neoadjuvant portion of the study is not sufficiently transparent. The precise composition of the study population is not clear, i.e., the doses and number of cycles used to treat patients, the number of patients who received reduced or delayed doses, and the number of patients who discontinued neoadjuvant treatment. The German specialists therefore recommend that adjuvant administration of capecitabine in the post-neoadjuvant setting of patients with TNBC should only be done in selected cases and after a detailed discussion of the risks and benefits with these high-risk patients.

The German specialists have the opinion that this should not just apply to the administration of capecitabine but also more generally when a patient with TNBC does not achieve pathologic complete remission ( $P C R$ ) with neoadjuvant therapy. Outside of clinical trials, such patients should only receive post-neoadjuvant chemotherapy on a case-by-case basis. 55\% of the St. Gallen panelists voted in favor of post-neoadjuvant chemotherapy.

Because of the more unfavorable prognosis of patients with TNBC who do not respond or show only limited response to neoadjuvant therapy, it was proposed that these patients should where possible - receive treatment as part of a clinical trial. The
German experts agreed with the vote of the St. Gallen panel on this point.

\section{Preventing alopecia}

Alopecia is a common side effect of chemotherapy and much dreaded by patients. Results from recent studies appear to indicate that constant cooling of the scalp using specially designed cooling caps can reduce or even prevent hair loss in some patients [31]. The St. Gallen panelists and the German experts consider this to be an interesting, new, supportive development.

\section{Adjuvant use of bone-modifying therapy}

Adjuvant use of a bisphosphonate (zoledronic acid every six months or daily oral clodronate) in addition to adjuvant endocrine therapy in postmenopausal patients can extend the disease-free survival (DFS) period. This applies irrespective of the bone mineral density of the affected woman. However, a meta-analysis [32] of the adjuvant use of bisphosphonates showed that only patients with lymph node involvement benefited from bisphosphonate therapy.

This also applies to premenopausal patients if these patients receive a $\mathrm{GnRH}$-analogue in addition to adjuvant endocrine therapy is new. This new recommendation is based on data from the Austrian ABCSG 12 study [33]. Due to the lack of data from corresponding studies, the adjuvant administration of denosumab (60 mg, every 6 months) is currently not indicated. The German specialists agree with the respective majority votes of the St. Gallen panelists.

\section{Special Situations}

\section{Older patients}

The German specialists agree with the vote by the St. Gallen panelists whereby the use of standard adjuvant (chemo-) therapy should not depend on patient age per se. The treatment decision must be guided by the patient's comorbidities, remaining life expectancy, stage of disease, and the patient's personal preferences. Similarly, the St. Gallen panelists do not give a maximum age after which adjuvant chemotherapy is no longer indicated.

This also applies to the indication for adjuvant radiotherapy in postmenopausal patients if the patient previously had breast-conserving surgery, adjuvant endocrine therapy is planned, and the patient is low-risk and has estrogen receptor-positive breast cancer without lymph node involvement. The indication for adjuvant radiation should be based on life expectancy $(<10$ years yes/no) and on potential comorbidities.

\section{Breast cancer and pregnancy}

If the patient wishes to become pregnant after she has completed primary therapy, adjuvant endocrine treatment can be paused after an in-depth discussion of the risks and benefits with the patient. The current data recommend that patients should receive endocrine adjuvant therapy for at least 18 months prior to becoming pregnant. The German specialists point out that the benefit of adjuvant endocrine therapy is correlated with the duration 
of therapy. Moreover, there are currently no data on the oncologic safety of pausing adjuvant endocrine therapy. This must explicitly be discussed with the patient. In principle, the patient's individual risk should be referred to in the consultation. If the patient wishes to have children, therapy planning should include encouraging the patient to visit a fertility clinic.

\section{Male breast cancer}

Male breast cancer is usually estrogen receptor-positive, and standard therapy consists of adjuvant treatment with tamoxifen. According to the majority vote of the St. Gallen panelists, a vote with which the German experts concur, adjuvant treatment with an aromatase inhibitor in combination with an LHRH-analog is also an option. Treatment with only an aromatase inhibitor is not an option.

\section{Is Genetic Testing for High-risk Mutations Useful?}

The question whether genetic testing should be generally recommended or recommended to certain groups has been discussed many times. The general principle is that the indication for genetic testing is only relative as long as it does not have therapeutic/ prophylactic consequences. Voting at the St. Gallen conference focused on the genetic testing of high-risk mutations such as $B R C A 1 / 2$ testing. The panelists voted almost unanimously in favor of recommending genetic testing to or discussing it with women from high-risk families (clear positive family history).

The majority of St. Gallen panelists voted in favor of genetic testing to patients who are younger than 40 years at primary diagnosis. The German experts point out that this differs from the AGO guidelines [1]. AGO recommends general testing without a positive family history for patients under the age of 36 years [1]. This lower age is based on the at least $10 \%$ higher probability of $B R C A 1 / 2$ mutations in these women.

The German specialists agree with the St. Gallen panelists that an age cut-off of less than 50 years is unsuitable for recommending genetic testing to patients without a familial history. There is therefore no general indication that patients below the age of 50 years should be tested. The situation is different for patients with TNBC. The St. Gallen panelists and the German specialists recommend that these patients undergo genetic testing if they are younger than 60 years of age at primary diagnosis.

The St. Gallen panelists and the German specialists agree that confirmation of BRCA1/2 mutation will affect the decision on surgical treatment as well as further prophylactic measures. The majority of St. Gallen panelists also believe that this will affect systemic therapy. The German specialists do not agree with the voting result for early breast cancer and refer to the AGO recommendations on neoadjuvant and post-neoadjuvant therapy in patients with TNBC [1]. The group of German specialists add that testing for the high-risk PALB2 mutation in addition to BRCA1/2 testing could also be an option if there is a positive familial history and the patient is $\leq 35$ years of age.

\section{Targeted Intervention Through Diet and Increased Physical Exercise?}

The German experts do not agree with the majority vote of the St. Gallen panelists who stated that patients with breast cancer require a special diet and should do more exercise. In general, patients should try not to be significantly overweight, and they should be supported in their endeavor at healthy physical exercise and a balanced diet to improve overall well-being. However, the German specialists have the opinion that lifestyle interventions over and above normal follow-up are not recommended, as there is no evidence of a significant reduction in the risk of recurrence and no positive impact on breast cancer-specific survival rates has been established.

\section{Acknowledgement}

The post-St. Gallen meeting was organized by Aurikamed Institute $\mathrm{GmbH}$ and was made possible by a non-restrictive grant from Celgene $\mathrm{GmbH}$, Munich. Compilation of the manuscript was exclusively the responsibility of the authors of the writing committee. The authors would like to thank Ms. Birgit-Kristin Pohlmann, Nordkirchen for her editorial support.

\section{Conflict of Interest}

Prof. Michael Untch has no conflict of interest. Prof. Jens Huober received honoraria from Celgene, Roche, Novartis, Hexal, Pfizer and TEVA. Prof. Christian Jackisch received a travel grant from Aurikamed. Prof. Andreas Schneeweiss received honoraria from Roche, Celgene, AstraZeneca, Pfizer, Novartis, MCl Deutschland, Aurikamed and Georg Thieme Verlag. Prof. Nadia Harbeck received honoraria from Agendia, Amgen, Celgene, Genomic Health, Lilly, MSD, Nanostring, Novartis, Pfizer, Roche, and Sandoz. PD Dr. med. Cornelia Liedtke received honoraria from Genomic Health, Roche, Celgene and received funding for research from Eisai. Prof. Sara Brucker has no conflict of interest. Prof. Peter Dall received honoraria from Roche, Novartis, AstraZeneca, Pfizer, TEVA. Prof. Carsten Denkert received honoraria from AstraZeneca, Pfizer, Celgene, TEVA, Myriad and holds shares in Sividon Diagnostics, Cologne. Prof. Peter A. Fasching received honoraria from Amgen, Novartis, Roche, and Pfizer, and received funding for research from Novartis. Prof. Tanja Fehm has no conflict of interest. Prof. Bernd Gerber received honoraria from AstraZeneca, Novartis, Roche, and Celgene. Prof. Wolfgang Janni has no conflict of interest. Prof. Thorsten Kühn has no conflict of interest. Prof. Diana Lüftner has no conflict of interest. Prof. Volker Möbus received honoraria from Amgen, Roche, and Celgene, and received funding for research from Amgen. Prof. Volkmar Müller received honoraria from Amgen, AstraZeneca, Celgene, Daiichi-Sankyo, Eisai, Pfizer, Pierre-Fabre, Nektar, Novartis, Roche, Teva and Janssen-Cilag. Prof. Achim Rody received honoraria from Roche, AstraZeneca, Pfizer, Celgene, Eisai, and Novartis, and received funding for research from Eisai. Prof. Peter Sinn has no conflict of interest. PD Marc Thill received honoraria from AstraZeneca, Celgene, Genomic Health, Novartis, Roche, Amgen, Teva, Myriad, pfmMedi- 
cal, Pfizer, RTI Surgical, Boeringer Ingelheim and funding for research from Genomic Health. Prof. Christoph Thomssen received honoraria from AstraZeneca, Celgene, Genomic Health, Novartis, NanoString, Pfizer, Roche and funding for research from NanoString.

\section{References}

[1] Diagnosis and treatment of patients with primary and metastatic breast cancer (Version 2017 1D). Online: www.ago-online.de; last access: 23.03.2017

[2] Jagsi R, Chadha M, Moni J et al. Radiation field design in the ACOSOG Z0011 (Alliance) Trial. J Clin Oncol 2014; 32: 3600-3606

[3] Kuehn T, Bauerfeind I, Fehm T et al. Sentinel-lymph-node biopsy in patients with breast cancer before and after neoadjuvant chemotherapy (SENTINA): a prospective, multicentre cohort study. Lancet Oncol 2013; 14: 609-618

[4] Online: www.astro.org; last access: 24.04.2017

[5] Online: www.estro.org; last access: 24.04.2017

[6] Smith BD, Arthur DW, Buchholz TA et al. Consensus Statement der ASTRO. Int J Rad Oncol Bio Phys 2009; 74: 987-1001

[7] Polgàr C, Van Limbergen E, Pötter $R$ et al. Patient selection for accelerated partial-breast irradiation (APBI) after breast-conserving surgery: recommendations of the Groupe Européen de Curiethérapie-European Society for Therapeutic Radiology and Oncology (GEC-ESTRO) breast cancer working group based on clinical evidence (2009). Radiother Oncol 2010; 94: 264-273

[8] Donker M, van Tienhoven G, Straver ME et al. Radiotherapy or surgery of the axilla after a positive sentinel node in breast cancer (EORTC 1098122023 AMAROS): a randomised, multicentre, open-label, phase 3 noninferiority trial. Lancet Oncol 2014; 15: 1303-1310

[9] Buus R, Sestak I, Kronenwett R et al. Comparison of EndoPredict and EPclin with Oncotype DX Recurrence Score for prediction of risk of distant recurrence after endocrine therapy. J Natl Cancer Inst 2016; 108: djw 149

[10] Sestak I, Buus R, Cuzick J et al. Comprehensive comparison of prognostic signatures for breast cancer recurrence in TransATAC. SABCS 2016, S605

[11] Francis PA, Regan MM, Fleming GF et al. Adjuvant ovarian suppression in premenopausal breast cancer. N Engl J Med 2015; 372: 436-446

[12] Pagani O, Regan MM, Francis PA; TEXT and SOFT Investigators; International Breast Cancer Study Group. Exemestane with ovarian suppression in premenopausal breast cancer. N Engl J Med 2014; 371: 1358-1359

[13] Cuzick J, Sestak J, Baum M et al. Effect of anastrozole and tamoxifen as adjuvant treatment for early-stage breast cancer: 10 year analysis of the ATAC trial. Lancet Oncol 2010; 11: 1135-1141

[14] Regan MM, Neven P, Giobbie-Hurder A et al. Assessment of letrozole and tamoxifen alone and in sequence for postmenopausal women with steroid hormone receptor-positive breast cancer: the BIG 1-98 randomised clinical trial at 8.1 years median follow-up. Lancet Oncol 2011; 12: 11011108

[15] Sparano JA, Gray RJ, Makower DF et al. Prospective validation of 21-gene expression assay in breast cancer. N Engl J Med 2015; 373: 2005-2014

[16] Nitz U. Prospective WSG Phase III PlanB trial: Clinical outcome at 5-year follow up and impact of 21 Gene Recurrence Score result, central/localpathological review of grade, ER, PR and Ki67 in HR+/HER2- high risk node-negative and -positive breast cancer. Vortrag ESMO/ECCO-Jahrestagung 2016, LBA 8
[17] Gluz O, Nitz UA, Christgen M et al. West German Study Group Phase III Plan B Trial: first prospective outcome data for the 21-gene recurrence score assay and concordance of prognostic markers by central and local pathology assessment. J Clin Oncol 2016; 24: 2341-2349

[18] Cardoso F, van't Veer LJ, Bogaerts J et al. 70-Gene signature as an aid to treatment decisions in early-stage breast cancer. N Engl J Med 2016; 375: 717-729

[19] Vaz-Luis I, Ottesen RA, Hughes ME et al. Outcomes by tumor subtype and treatment pattern in women with small, node-negative breast cancer: a multi-institutional study. J Clin Oncol 2014; 32: 2142-2150

[20] Ignatov T, Eggemann H, Burger E et al. Management of small T1a/b breast cancer by tumor subtype. Breast Cancer Res Treat 2017; 163: $111-118$

[21] Kolben T, Harbeck N, Wuerstlein R et al. Endocrine sensitivity is decisive for patient outcome in small node-negative breast cancers (BC) (pT1a,b) - results from the Munich Cancer Registry. Breast 2014; 24: 24-31

[22] National Comprehensive Cancer Network. Online: www.nccn.org; last access: 24.04 .2017

[23] von Minckwitz G, Schneeweiss A, Loibl S et al. Neoadjuvant carboplatin in patients with triple-negative and HER2-positive early breast cancer (GeparSixto; GBG 66): a randomised phase 2 trial. Lancet Oncol 2014; 15: 747-756

[24] Wolff AC, Hammond ME, Hicks DG et al. Recommendations for human epidermal growth factor receptor 2 testing in breast cancer: American Society of Clinical Oncology/College of American Pathologists clinical practice guidelines update. J Clin Oncol 2013; 31: 3997-4013

[25] Slamon DJ, Eiermann W, Robert NJ et al. Ten-year follow-up of BCIRG-006 comparing doxorubicin plus cyclophosphamide followed by docetaxel with doxorubicin plus cyclophosphamide followed by docetaxel and trastuzumab with docetaxel, carboplatin and trastuzumab in HER2-positive early breast cancer patients. SABCS 2015, S5-04

[26] Von Minckwitz G, Procter M], De Azambuja E et al. Adjuvant pertuzumab and trastuzumab in early HER2-positive breast cancer. N Engl J Med 2017; DOI: 10.1056/NEJMoa1703643

[27] Pivot XB, Bondarenko I, Dvorkin M et al. A randomized, double-blind phase III study comparing SB3 with originator trastuzumab in patients treated by neoadjuvant therapy for HER2-positive early breast cancer. ASCO 2017, Poster 509

[28] Stebbing J, Baranau YV, Baryash V et al. Double-blind, randomized phase III study to compare the efficacy and safety of CT-P6, trastuzumab biosimilar candidate versus trastuzumab as neoadjuvant treatment in HER2 positive early breast cancer. ASCO 2017, Poster 510

[29] Untch M, Jackisch C, Schneeweiss A et al. Nab-paclitaxel versus solventbased paclitaxel in neoadjuvant chemotherapy for early breast cancer (GeparSepto-GBG 69): a randomised, phase 3 trial. Lancet Oncol 2016; 17: 345-356

[30] Masuda N, Lee S], Ohtani S et al. Adjuvant capecitabine for breast cancer after preoperative chemotherapy. N Engl J Med. 2017; 376: 2147-2159

[31] Nangia J, Wang T, Niravath P et al. Scalp Cooling Alopecia Prevention Trial. SABCS 2016, S5-02

[32] Early Breast Cancer Trialists' Collaborative Group (EBCTCG), Coleman R, Powles $\mathrm{T}$ et al. Adjuvant bisphosphonate treatment in early breast cancer: meta-analyses of individual patient data from randomised trials. Lancet 2015; 386: 1353-1361

[33] Gnant M, Mlineritsch B, Stoeger $\mathrm{H}$ et al. Adjuvant endocrine therapy plus zoledronic acid in premenopausal women with early-stage breast cancer: 62-month follow-up from the ABCSG-12 randomised trial. Lancet Oncol 2011; 12: 631-641 